\title{
Mixed Mode Delamination in Carbon Nanotube/Nanofiber Interlayered Composites
}

\author{
Ozge Kaynan $^{\mathrm{a}, \mathrm{c},}$, Yagmur Atescan ${ }^{\mathrm{b}, \mathrm{c}, \mathrm{d}}$, Elif Ozden-Yenigun ${ }^{\mathrm{a}, \mathrm{c}, \mathrm{e}, *}$, Hulya Cebeci $^{\mathrm{b}, \mathrm{c}, *}$ \\ ${ }^{a}$ Department of Textile Engineering, Istanbul Technical University, Istanbul, 34469, Turkey \\ ${ }^{b}$ Department of Aeronautical Engineering, Faculty of Aeronautics and Astronautics, Istanbul \\ Technical University, Maslak, Istanbul, 34469, Turkey \\ c ITU Aerospace Research Center, Maslak, Istanbul, 34469, Turkey \\ ${ }^{\mathrm{d}}$ Current address: Department of Aerospace Engineering, Pennsylvania State University, 229 \\ Hammond, University Park, PA 16802, USA \\ ${ }^{\text {e }}$ Current address: School of Design, Textiles, Royal College of Art, SW7 2EU, London, \\ United Kingdom
}
*Corresponding authors: E-mail addresses: Elif Ozden-Yenigun; elif.ozden-yenigun@rca.ac.uk
Hulya Cebeci; hulya.cebeci@itu.edu.tr ABSTRACT

Laminated composites mostly suffer from layer separation and/or delamination, which may affect the stiffness, strength and lifetime of structures. In this study, we aim to produce micronscale thin carbon nanotubes (CNTs) reinforced adhesive nanofibrous interleaves and to explore their effectiveness when incorporated into structural composites. Neat polyvinyl butyral (PVB) and solutions containing low fractions of CNTs from 0.5 to 2 wt.\% were electrospun directly onto carbon fiber prepregs. These interlayered laminates were cured above the glass transition temperature $\left(T_{g}\right)$ of PVB to achieve strong interlaminar binding and also to resist crack reinitiation. The effect of CNTs presence and their mass fractions both on total Mixed-Mode I+II fracture toughness $\left(G_{C}\right)$ and crack length was investigated under Mixed-Mode I+II loading. Almost 2-fold increase in $G_{C}$ was reported in interlayered composites compared to noninterlayered laminates, associated to toughening effect of adhesive PVB/CNTs nanofibrous interlayers. Furthermore, the post-fracture analysis revealed the aid of CNTs interleaves in retarding delamination and afterward stabilization of crack propagation. 
Keywords: Carbon nanotubes, Nanofibers, Electrospinning, Interlaminar fracture toughness, Mixed-Mode delamination

\section{Introduction}

The load bearing capability and lifetime of composite structures can be enhanced by enabling delayed and/or prevented delamination mechanism. [1-4]. Among widely known approaches including designing lay-up sequence and stitching to minimize interlaminar stress, novel approaches such as tailoring the interlaminar regions using nanofibers and stiff nanomaterials between two subsequent plies have been studied. Since these interfacial regions were resin rich, adding sub-phases in these planes caused retarding crack propagation which was referred as interlayer toughening [5-15]. These mechanisms can be promoted by the presence of solely nanoparticles [16-19], films [20-22] and nanofiber reinforcements [23-28] and their several combinations $[15,24]$. As an effective interface interaction, the insertion of thin nanofibrous interlayers has received great attention particularly to improve through-thickness and in-plane toughening of fiber reinforced composites [15, 24, 29, 30]. Having an ease on the implementation of these interlayers and their scalable production make them promising candidates, hence the toughening strategies of these fibrous nanolayers and their effect on the fracture toughness of laminated structures were investigated under different loading conditions. Electrospinning, one of the most convenient technique to obtain uniform distribution of nanoscale fibers, provides nanofibrous coating with high surface area to volume ratio, and large porosity. Once, these nanofibers applied directly onto the fabric surface, the arisen problems with the use of nanomaterials such as increased resin viscosity and inhomogeneous dispersion would be of concern. [31]. In addition, entangled nanofibers make a positive contribution on the interlaminar fracture resistance much like hoops and loops in Velcro while showing notable enhancement in crack deflection and crack bridging [26]. 
Literature studies showed that carbon nanotubes (CNTs) are also effective reinforcing elements to enhance ply by ply adhesion, fracture toughness and resistance to delamination. When CNTs were combined with nanofibrous webs, without any drastic change in weight, a remarkable improvement in mechanical properties of toughened composites was observed [15, 24, 32]. Sihn et al. studied the effect of CNTs/thermoplastics such as polycarbonate, poly(phenylene oxide) and polystyrene nanofibers on the delamination characteristics of composites when they are placed as nano-interleaves between the ply interfaces. They reported increased stress for the onset of delamination by about $8 \%$ and the reduced numbers of microcracks at the delamination stress by $21.6 \%$ for polycarbonate/CNTs nanofiber interlayered composites without any weight penalty [33]. Later, Bilge et al. [15] fabricated epoxy compatible polystyrene-co-glycidly methacrylate $\mathrm{P}($ St-co-GMA)/multi-walled carbon nanotubes (MWCNTs) mats by electrospinning, and used them as interleaves in carbon fiber epoxy prepregs. With additional weight of electrospun mats as low as $0.2 \%$ of the prepreg ply weight, they obtained $17 \%$ increase in flexural strength, and $70 \%$ increase in Mode II strain energy release rate by promoting in-situ crosslinking of nanofibers.

Under quasi-static loading conditions, the delamination resistance through crack propagation by solely Mode I (opening) and Mode II (shearing) has been widely investigated [4, 15, 34, 35]. For instance, Palazzetti et al. studied Mode I $\left(G_{I}\right)$ and Mode II $\left(G_{I I}\right)$ strain energy release rate of polyamide (PA6.6) nanofiber interleaved unidirectional and woven carbon laminates. The results showed that these nanofibrous layers have stronger contribution to $G_{I I}$ than $G_{I}$ and exhibited about two-fold increase compared to non-interlayered laminates [36]. Beckermann et al. explored the potential of electrospun fibrous veils including PA6.6 and polyvinyl butyral (PVB) to improve fracture toughness under Mode I and Mode II loadings [37]. PVB incorporated composites demonstrated $16 \%$ improvement in $G_{I}$; whereas $8 \%$ decrease in $G_{I I}$ noted attributed to low tensile strength of bulky PVB that resisted the micro crack opening. 
Even though, PVB based resins were expected to be promising materials to be used in laminated composites due to their strong binding and adhesion to metallic, polymer and glass surfaces, PVB microfibers used in this reference study [37] were not found effective in bridging the microcracks during Mode II fracture. However, Mixed-Mode I+II bending test would provide more realistic conditions to simulate laminated structures subjected to complex loading conditions when in service [4]. The Mixed-Mode I+II bending test method, developed by Reeder et al. [38], enables to work with varying Mode I and Mode II loading ratio in the same sample dimension to determine interlaminar fracture toughness [4, 39]. Furthermore, it allows to characterize delamination re-initiation and growth for any defined Mode I and Mode II loading ratio [40]. Yayla et al. [41], studied the fracture surfaces of carbon fiber reinforced polymer composites under Mode I, Mode II and Mixed-Mode I+II loading. As revealed by scanning electron microscope (SEM) micrographs, Mode I failure was primarily initiated in the matrix region while interface between carbon fiber and matrix phase were dominantly failed under Mode II loading. Silva et al. studied the influence of small quantities of nanoparticles such as nanoclay and MWCNTs, on the interlaminar fracture toughness of glass/epoxy laminates under Mode I, Mode II and Mixed- I+II loadings. Dispersed 3 wt.\% of nanoclay and 0.5 wt. \% of MWCNTs showed an increase in the Mixed-Mode I+II interlaminar fracture toughness up to $39 \%$ and $23 \%$ respectively. At higher loading of MWCNTs, due to poor dispersion and distribution of particles, the enhancement was depressed and decreased to $14 \%$. The hypothesis is that thin interlayers of polymeric nanofibers with an enhanced capability of adhesion would be beneficial to act as adhesive sub-phases in between the plies of composite structure [29]. PVB has been accepted as compatible host for CNTs within its good adhesion and high fracture toughness properties [42]. Imaizumi et al. [42, 43] successfully produced PVB/CNTs electrospun nanofibers and twisted them to have composite nanofiber yarns. Alhazov et al. [44] reported a significant improvement in tensile strength and Young's modulus 
of these composite nanofibers within the good dispersion of CNTs in PVB matrix and also briefly investigated the impact resistance of laminated glass by increased PVB/CNTs interlayer energy absorption. Charitidis et al. [45] integrated CNTs into PVB nanocomposites to enhance electrical and thermal properties. All these researchers pointed out the compatibility of PVB resin for CNTs. On the other hand, the electrospinning of PVB solutions containing CNTs is a complicated process, where suspending the CNTs in the polymer solution and ensuring the formation of homogenous stable suspensions prior to electrospinning are the frontline challenges [24]. Thus, PVB-CNTs inter-molecular interactions influence the degree of nanotube dispersion and polymer re-aggregation. Computational studies [46] pointed out the slight repulsions between CNTs and PVB chains might lead to large morphological differences and CNTs bundles in polymeric solutions. However, it is worthy to note that electrohydrodynamic spinning processes such as electrospinning assist to disperse conductive CNTs individually by aligned electrical field.

To date, there have been several studies exploring the effect of electrospun nanofiber interleaves on fracture toughness of laminated composites [15, 24, 29, 30, 37]. Besides, CNT reinforced interleaves were also introduced to reinforce composites and their contribution was addressed under Mode I, Mode II and Mixed I+II mode loadings [4, 33]. Till now, the researchers have not put efforts to tackle the synergetic effect of composite adhesive networks triggered by thermal transitions. This study attempts to reveal the effect of micron-scale thin adhesive PVB nanofiber interlayers reinforced by CNTs at low weight fractions such as $0.5,1,2$ wt.\% on failure mechanism under Mixed-Mode I+II bending. The hypothesis is that not only adhesive PVB nanofiber network [37, 47] but also stiff CNTs [24] would assist to resist delamination under complex loading conditions. CNTs embedded PVB solution was directly electrospun onto the carbon fiber prepregs to ease implementation of nanofibers. To simulate a genuine loading condition, Mixed-Mode I+II bending tests were carried out for hybrid laminates cured 
above the glass transition temperature $\left(T_{g}\right)$ of PVB. Nanointerlayered composites have shown up to 2-fold increase in total Mixed-Mode I+II fracture toughness $\left(G_{C}\right)$ compared to noninterlayered laminates, which was attributed to toughening effect of adhesive PVB/CNTs nanofibrous interlayers. The synergetic effect of stiff CNTs and adhesive PVB nanofibers prompted plasticization and deflected induced crack propagation by interleaving. Fractography also revealed the role of CNTs incorporated layers on retarding delamination and crack propagation stabilization.

\section{Material and Experimental Procedure}

\subsection{Electrospinning of PVB/CNTs Nanofibers and laminate manufacturing}

Polymer solutions were prepared by dissolving PVB (Butvar®, average MW 50,000-80,000 g/mol, Sigma Aldrich) 10 wt.\% in methanol (Sigma Aldrich). MWCNTs (Sigma Aldrich) purity of $95 \%$ was then added to improve the mechanical properties of electrospun nanofibrous webs. The nominal diameter and length of MWCNTs were 6-9 $\mathrm{nm}$ and $5 \mu \mathrm{m}$, respectively. No surface modification on CNTs was employed in this work. CNTs were dispersed in polymer solutions at different mass fractions/concentrations $(0.5 \%, 1 \%$ and $2 \%)$ by mechanical stirring for 24 hours (hr). All chemicals were used without further purification. The polymer solution was electrospun directly onto twill 2x2 carbon/epoxy prepreg layers (SPM Composite Advanced Materials Technologies Company, VTP H310 resin system), as depicted in Fig 1a. Applied voltage, solution flow rate and tip to ground distance were set at $15 \mathrm{kV}, 0.5 \mathrm{~mL} / \mathrm{hr}$ and $15 \mathrm{~cm}$, respectively during electrospinning performed in an Argeteknolab Co. device. Consequently, a thin layer of nanofibrous mat (with mean fiber diameter in the range of 130-200 nm) with an additional weight as low as $0.01 \%$ of the total composite weight was fully impregnated by the prepreg surface without creating any non-wetted surfaces as displayed in Fig S1. Throughout the process, no precipitation in electrospinning solution was observed and completely opaque solutions were stable over a long term. 

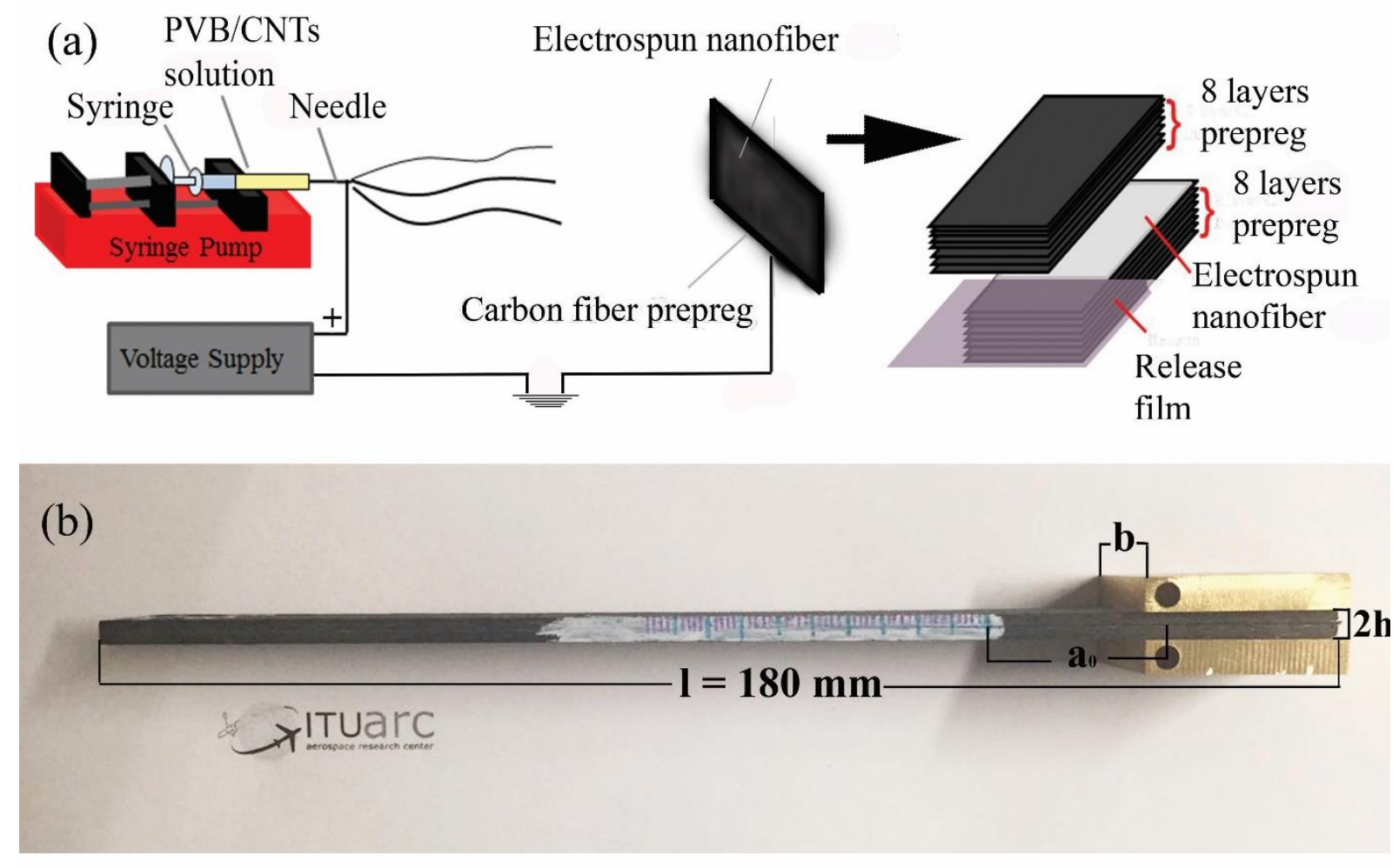

(c)

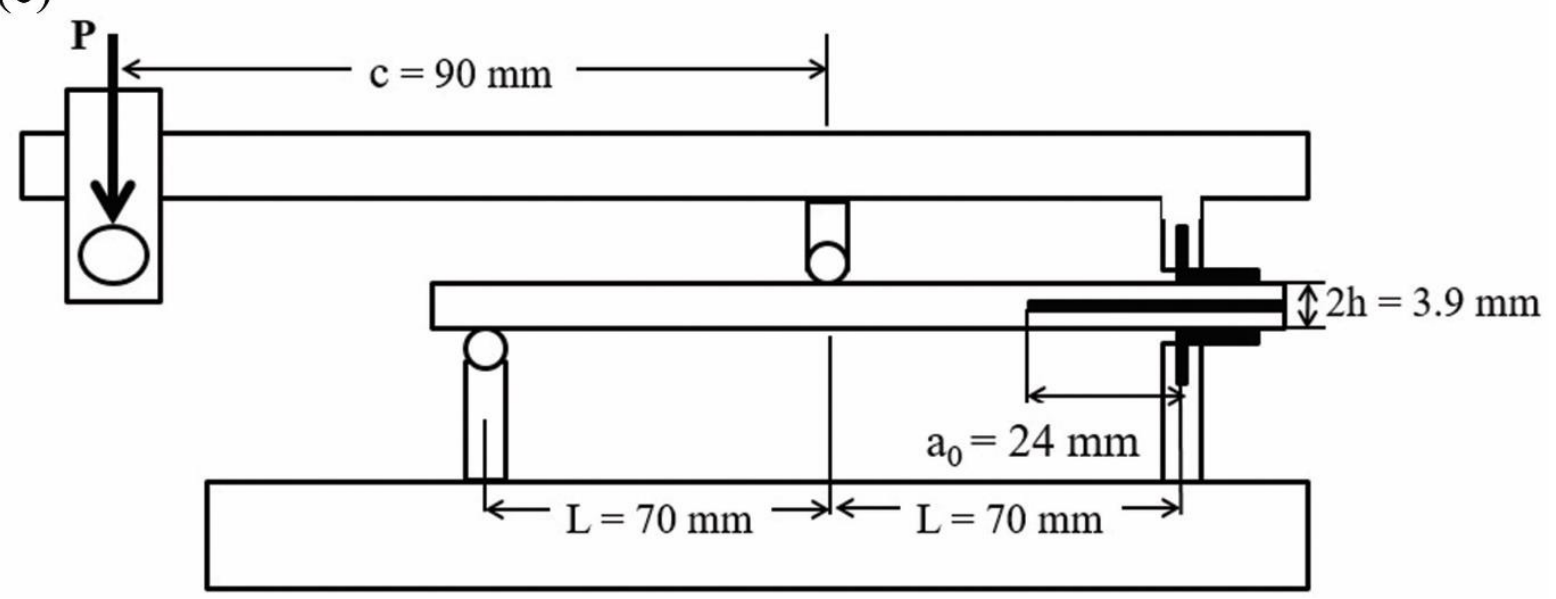

Fig. 1 (a) Illustration on the fabrication of PVB and PVB/CNTs nanofiber interlayered laminates (b) Mixed-Mode bending (MMB) test specimen (c) Sketch of MMB test apparatus displaying the parameters given in Eq. 1 and Eq. 6-8.

For fabrication of Mixed-Mode I+II delamination test specimens, 16 subsequent carbon fiber prepreg plies were stacked to obtain the thickness specified by ASTM-D6671 [39]. In interlayered specimens, neat PVB and PVB/CNTs nanofibers were deposited on the mid-layer 
where release film was placed onto as displayed in Fig 1a. For reference specimens, release film was also added to mid-plane. After stacking the plies for intended laminates, each stack was put on a metallic tooling plate along with a release film with thickness of $50 \mu \mathrm{m}$, and peel ply. Another sheet of peel ply was then laid on the top of plies followed by a nonwoven breather layer. Next, the whole lay-up was vacuum bagged and kept under vacuum during the cure cycle. Prepreg stacks were cured at $150^{\circ} \mathrm{C}$ for $2 \mathrm{hr}$ under -1 atm vacuum, which is above $T_{g}$ of PVB. Curing process was performed out of autoclave on a hot plate without the requirement of additional processes including air bubble removal. As displayed in Fig 1b, two-sided hinges were attached to delamination end by using adhesive glue. Before bonding each surface was sanded and cleaned with acetone to improve mechanical interlocking between composite and metal surfaces. To follow crack propagation by eye examination, control lines with $0.5 \mathrm{~mm}$ intervals were drawn from crack initiation point to end of the specimens, as seen in Fig $\mathbf{1 b}$.

\subsection{Characterization and Mixed-Mode I+II Delamination Testing of Laminates}

The morphologies of neat PVB and PVB/CNTs fibrous webs and fracture surfaces of reference and interlayered composites were evaluated by imaging using $15 \mathrm{keV}$ secondary electrons in field-emission gun equipped scanning electron microscope (SEM, LEO 1530VP). The diameter of electrospun nanofibers was estimated by ImageJ software. The mean fiber diameter and distribution were determined from at least 40 measurements on the randomly selected fibers. To verify the presence of CNTs in the composite nanofiber mats, Raman spectroscopy (Renishaw's Raman) with $532 \mathrm{~nm}$ laser was used in the range $100-3200 \mathrm{~cm}^{-1}$. The thickness of dry nanofibrous interlayer was also measured as $85 \mu \mathrm{m}$ by optical microscope images.

Mixed-Mode I+II delamination testing was performed to investigate both the effect of neat PVB and PVB/CNTs nanofiber interlayers using Shimadzu AGX Universal Testing Machine with load cell of $100 \mathrm{kN}$. Load and axial displacement were recorded by software while crack growth was monitored simultaneously using a video recording camera system. Mixed-Mode I+II 
delamination tests were conducted according to ASTM-D6671 standard [39] using a MixedMode bending (MMB) test apparatus (Fig 1c). MMB apparatus is a combination of a double cantilever beam (DCB) (Mode I) specimen and an end notch flexure ENF (Mode II) specimen, which introduces Mode I loading at the end of lever and Mode II loading at the fulcrum [40]. Throughout this study, reference and nano-interlayered composites were tested at same modal ratio of $30 \%$ based on previous study, calculated as $\left(G_{I I} /\left(G_{I}+G_{I I}\right)\right)$ where $G_{I}$ and $G_{I I}$ represent Mode I and Mode II strain energy release rate, respectively, [4]. The lever length $c$ was derived by Eq. 1:

$$
c=\frac{12 \beta^{2}+3 \alpha+8 \beta \sqrt{3 \alpha}}{36 \beta^{2}-3 \alpha} L
$$

where $\alpha$ is the mode mixture transformation parameter for setting the lever length, $\beta$ is the nondimensional crack length correction parameter and $L$ is the half span length. $\alpha$ depends on modal ratio derived by Eq. 2 and $\beta$ was calculated from $E q .3$ depending on crack length correction parameter, $\chi$, which was computed as 1.45 from $E q .4$.

$$
\begin{gathered}
\alpha=\frac{1-\frac{G_{I I}}{G_{I}+G_{I I}}}{\frac{G_{I I}}{G_{I}+G_{I I}}} \\
\beta=\frac{\alpha+\chi h}{\alpha+0.42 \chi h} \\
\chi=\sqrt{\frac{E_{11}}{11 G_{13}}\left\{3-2\left(\frac{\Gamma}{1+\Gamma}\right)^{2}\right\}}
\end{gathered}
$$

$E q .4$ describes the calculation of $\chi$ where $E_{11}$ is longitudinal modulus of elasticity, $G_{13}$ is out of plane shear modulus for carbon fiber prepregs and $\Gamma$ is transverse modulus correction parameter. 


$$
\Gamma=1.18 \frac{\sqrt{E_{11} E_{22}}}{G_{13}}
$$

$\Gamma$ was derived from $E q .5$ where $E_{22}$ is the transverse modulus of elasticity. The values of $E_{11}$, $E_{22}$ and $G_{13}$ for $2 x 2$ twill carbon/epoxy prepregs were determined experimentally to be 100,100 and $5 \mathrm{GPa}$, respectively [48]. The lever length $c$ was set to $90 \mathrm{~mm}$. All tests were performed at a displacement rate of $0.5 \mathrm{~mm} / \mathrm{min}$ with applied preload of $10 \mathrm{~N}$. Elastic constants for composite materials and MMB test apparatus dimensions that were used to calculate Eq. 1-5, were also listed at Table 1.

Table 1 Elastic constants for 2x2 twill carbon/epoxy prepregs and used MMB test parameters

\begin{tabular}{ll}
\hline \multicolumn{1}{c}{ Parameters } & \multicolumn{1}{c}{ Values } \\
\hline Longitudinal modulus $\left(E_{11}\right)$ & $100 \mathrm{GPa}$ \\
Transverse modulus $\left(E_{22}\right)$ & $100 \mathrm{GPa}$ \\
Shear modulus $\left(G_{13}\right)$ & $5 \mathrm{GPa}$ \\
Modal ratio $\left(G_{I I} / G\right)$ & $30 \%$ \\
Half span length $(L)$ & $70 \mathrm{~mm}$ \\
\hline
\end{tabular}

$G_{C}$ is the sum of $G_{I}$ and $G_{I I}$ where $G_{I}$ and $G_{I I}$ were derived from $E q .6$ and 7, respectively.

$$
\begin{gathered}
G_{I}=\frac{12 P^{2}(3 c-L)^{2}}{16 b^{2} h^{3} L^{2} E_{1 f}}(\alpha+\chi h)^{2} \\
G_{I I}=\frac{9 P^{2}(c+L)^{2}}{16 b^{2} h^{3} L^{2} E_{1 f}}(\alpha+0.42 \chi h)^{2}
\end{gathered}
$$

$P$ is the applied load, $\alpha$ is the total debonding length, $b$ is width of the specimen and $E_{1 f}$ is the modulus of elasticity in the fiber direction which as calculated using Eq. 8:

$$
E_{1 f}=\frac{8\left(a_{0}+\chi h\right)^{3}(3 c-L)^{2}+\left[6\left(a_{0}+0.42 \chi h\right)^{3}+4 L^{3}\right](c+L)^{2}}{16 L^{2} b h^{3}\left(\frac{1}{m}-C_{s y s}\right)}
$$

where $\alpha_{0}$ is initial delamination length, $m$ is the slope of the force displacement curve, $h$ is the half thickness of test specimen and $C_{s y s}$ is the system compliance. All equations (as described in Eq. 1-Eq. 8) were derived from ASTM-D6671 standard [39]. Each test associated with the types of specimen was repeated at least 4 times for data analysis. 


\section{Results and Discussion}

Fig 2a-d show the morphologies of neat PVB and CNTs reinforced nanofibers obtained by varying the CNTs concentration from 0.5 to $2 \mathrm{wt} . \%$ at $15 \mathrm{kV}$ at constant collector distance of $15 \mathrm{~cm}$. Mean fiber diameter of fibers decreased from $200 \pm 5 \mathrm{~nm}$ to $131 \pm 8 \mathrm{~nm}$ by increasing CNTs concentration to 2 wt.\%, which can be attributed to two factors such as electrical conductivity and rheological changes in polymer solution [24, 42]. The addition of CNTs increases the electrical conductivity of solutions, while also causing a shear thinning effect in polymer solutions as reported in our previous study [24]. Hence, both the reduced viscosity during fiber formation primarily attributed to CNTs-PVB interactions and higher solution conductivity led to the thinner nanofibers as seen in Fig 2a-d. We should also note that increasing CNTs concentration did not cause the formation of bead-like structures and/or CNTs agglomerates where similar behavior was observed by $[42,49,50]$. In the first place, electrospinning aligns CNTs through electric field and eases flow-confinement and chargeinduced orientation [51]. Another reason for nanofiber formation without bead and/or CNTs agglomerations could be attributed to decreased solution viscosity with optimized electrospinning process parameters. However, Song et al. [50] observed topological defects such as CNTs entanglements, twisted parts and knots observed in CNTs/PAN electrospun nanofibers, and explained that all these uniformities could be led by extremely fast electrospinning process in which CNTs were only partially stretched in a millisecond. All these deviations in structures pointed prerequisites in process optimization, since CNTs do not have enough response time to form or dissipate large aggregates. Thus, we realized that after preliminary studies on defining optimal process parameters, web homogeneity was achieved at all CNTs concentrations. Besides, as seen in Fig 2a and Fig 2d, the mean fiber diameter of neat PVB fibers are almost same as 0.5 wt.\% CNTs reinforced PVB nanofibers, while CNTs caused slightly wider diameter distribution. 
Raman spectra of nanofibrous interlayers were obtained using a green laser $(\lambda=532 \mathrm{~nm})$ for determining the signature of the CNTs. Fig 3 shows the Raman spectra of the neat PVB and 2 wt. \% PVB/CNTs composite nanofibers. Among the characteristic peaks of CNTs detected by Raman spectroscopy, two peaks at c.a $1590 \mathrm{~cm}^{-1}(G)$ and $1352 \mathrm{~cm}^{-1}(D)$ could be clearly distinguished. $D$-band revealed at c.a. $1350 \mathrm{~cm}^{-1}$ corresponds to the presence of amorphous carbon and structural defects $\left(A_{l g}\right)$ and $G$-band displayed at $1580 \mathrm{~cm}^{-1}$ represents the graphite structures and tangential shearing mode of the carbon atom $\left(E_{2 g}\right)[46,52]$. Besides, Raman spectroscopy measurements from the surface of PVB/CNTs nanofibers demonstrated that it was possible to detect CNTs at such small amounts. Complimentary to Raman spectrum of pristine CNTs [53], the well distributed CNTs filling in the as-spun fibers was confirmed.

Depending on curing temperature, produced PVB/CNTs layers can be implemented within two forms; below $T_{g}$ of PVB as PVB/CNTs nanofibrous webs similar to earlier studies [54] or above $T_{g}$ as CNTs dispersed in an adhesive network. To this end, we performed composite curing at $150^{\circ} \mathrm{C}$, which is above $T_{g}$ of PVB (around $70^{\circ} \mathrm{C}$, see Fig S2) to have CNTs incorporated adhesive films as an alternative to other adhesive agents and conventional films. Delamination mechanism of nanofiber interlayered composites has been studied extensively in quasi-static loadings [23-25, 29, 30, 36, 54-57] and even has been investigated under high-strain rate [58]. Herein we aimed to explore the effect of single adhesive layer of neat PVB and PVB/CNTs nanofibers on re-initiation of cracking and delamination growth under Mixed-Mode I+II static loading. 

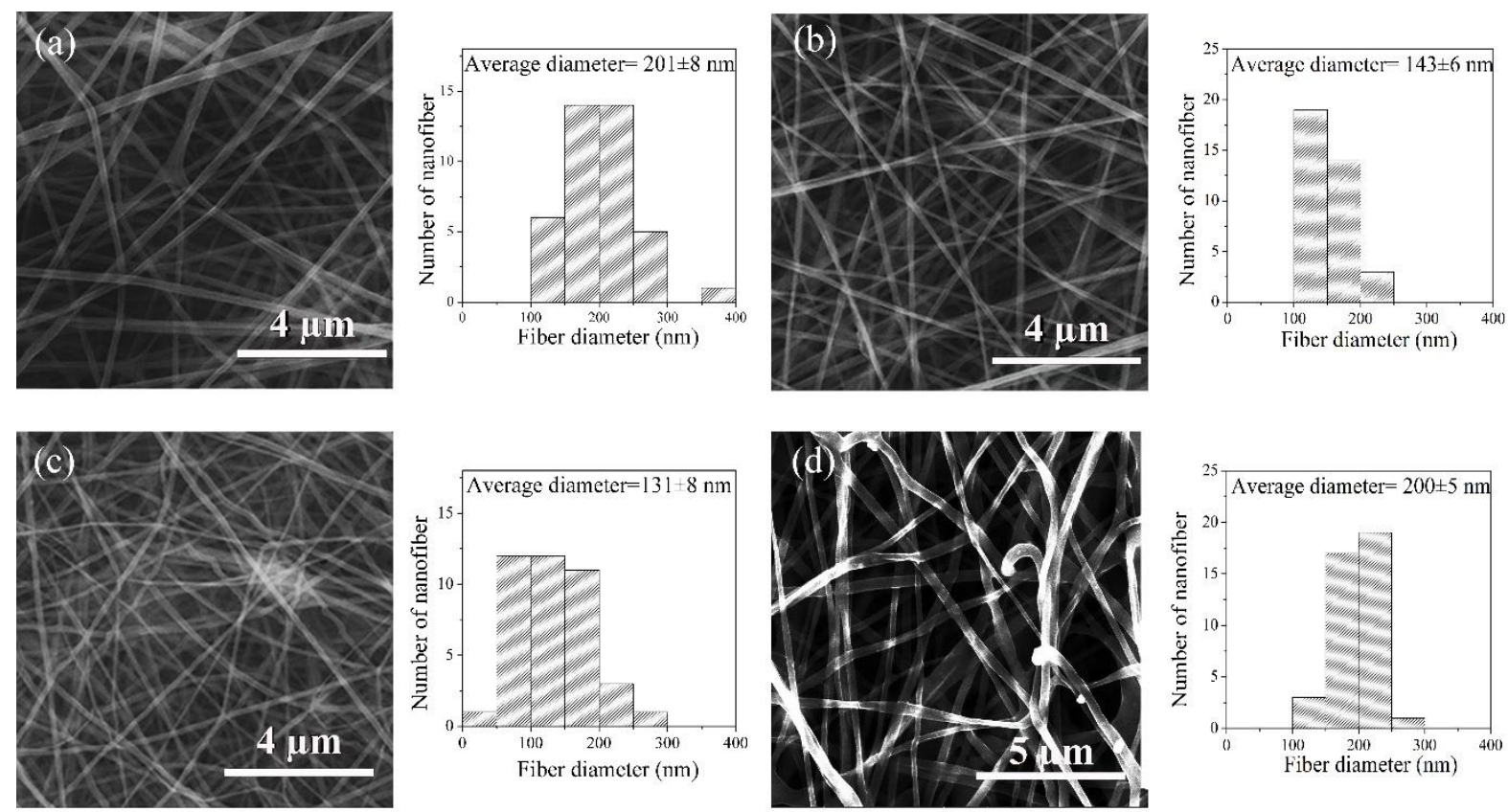

Fig. 2 SEM images of a) 0.5 wt.\%, b) 1 wt.\%, c) 2 wt. $\%$ CNTs reinforced and d) neat PVB nanofibrous interlayers with mean fiber diameter of $201 \pm 8 \mathrm{~nm}, 143 \pm 6 \mathrm{~nm}, 131 \pm 8 \mathrm{~nm}$, and $200 \pm 5 \mathrm{~nm}$, respectively.

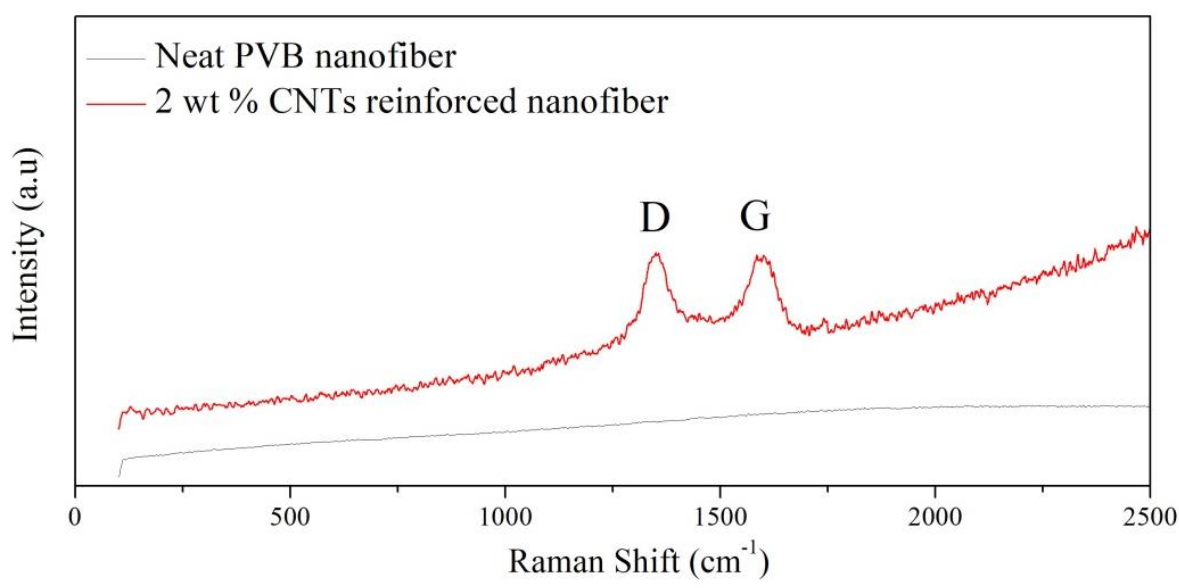

Fig. 3 Raman spectra of neat PVB nanofibers and 2 wt.\% CNTs reinforced nanofibrous interlayers revealing D peak at $1352 \mathrm{~cm}^{-1}$ and $\mathrm{G}$ peak at $1590 \mathrm{~cm}^{-1}$.

Fig 4 shows typical plots of the applied load vs. load point deflection of Mixed Mode I+II bending specimens for the five types of specimens, described in Section 2.2. Table 2 describes 
mean crack length, mean maximum load resisted to crack propagation and total $G_{C}$ of reference and interlayered composites when subjected to Mixed-Mode I+II loading. All four interlayered specimen types and reference non-interlayered composite exhibited the typical behavior of woven composites tested under Mixed-Mode I+II loading [4, 40, 59]. Fig 4 can be divided into two different zones to discuss the effect of interlayers on fracture mechanism. The first zone ends at c.a. displacement of $10 \mathrm{~mm}$, showed minor ply failures, as also tracked by Bilge et al. $[15,60]$. At this stage, as framed in Fig 4 neat PVB nanofibers and 0.5 wt.\% CNTs reinforced interlayers provided slightly better adhesion. On the other hand, increased concentration of CNTs eliminated the contribution of this adhesive network where inevitable CNTs clusters created local stress concentrators at the interface. The reference non-interlayered composites without any interlayers exhibited essentially linear profile in the first region of load displacement curve as partially zoomed in Fig 4, whereas interlayered composites demonstrated slight irregularities. In all Mixed-Mode I+II specimens, the first crack was initiated by the insertion of release film; hence crack re-initiation term was used to express formed new cracks during testing. Below displacement of $10 \mathrm{~mm}$, Fig 4 showed that neat PVB and 0.5 wt.\% CNTs interlayered laminates were more effective in interlaminar toughening. Beyond this point, as in 1 wt. $\%$ and 2 wt.\% CNTs nanofiber interlayered composites, CNTs bundles also acted as rigid fillers to arrest the crack, prevent or delay the expansion of microcracking within the matrixrich interface area [4]. Moreover, in all interlayered composites higher number of load increase cycles was observed until failure that was attributed to the effective adhesive interleaving. More importantly, neat PVB and 0.5 wt.\% CNTs nanofiber interlayered composite was characterized by multiple arrest mechanisms and moderate load drop compared to non-interleaved specimens. At higher CNTs concentrations as in 1 wt.\% and 2 wt.\% CNTs nanofiber interlayered composites, much higher crack resistance was noted. The difference in crack propagation paths indicated the possibility of different fracture resistance mechanisms. The role of interlayers was 
much clearer in the retardation of second crack re-initiation which occurred at around $5 \mathrm{~mm}$ in non-interlayered composites while it was prompted at around $8-10 \mathrm{~mm}$ in CNTs nanofiber interlayered composites. Nevertheless, for all interlayered specimens, adhesive layers assisted to arrest cracks and to retard the propagation seen at c.a $5 \mathrm{~mm}$. These stepwise moderate load drops interpreted as resistance to larger load deflections relied on both the effective stiffness of CNTs and good interfacial binding. The results showed that a single layer of $1 \mathrm{wt} \% \mathrm{CNTs}$ nanofiber interlayer resulted in $12 \%$ increase in maximum flexural load showing the optimum CNTs concentration among all variations in this study. In 2 wt.\% CNTs nanofiber interlayered composites, a slight decrease in resisted load was observed, but still showed higher $G_{C}$ due to increased crack length. It is important to note that total mean Mixed-Mode I+II fracture energy, $G_{C}$, was evaluated by means of $E q .6$ and $E q .7$ for all specimens. Mixed-Mode I+II energy at fracture, $G_{C F}$, as displayed in Table 2 was calculated at the crack length of 40 and $55 \mathrm{~mm}$ for reference and interlayered composites, respectively. For review, we also provided the real time videos of Mixed-Mode I+II bending tests for non-interlayered composite and 1 wt.\% CNTs nanofiber interlayered composite in Supporting Information.

Fig 5 demonstrates mean values of the total fracture energy under Mixed-Mode $\left(G_{C}=G_{I}+G_{I I}\right)$ vs delamination length. Each $G_{C}$ value was calculated both by monitoring crack propagation as seen in supporting videos and by interpreting tracked load data as suggested in ASTM-6671 [39]. Therefore, Fig 5 starts displaying at the crack length of $24 \mathrm{~mm}$ as the end of the inserted release film. It is clear that significant crack growth resistance was observed in nanointerlayered composites, as depicted in Fig 5. Up to crack length of $29 \mathrm{~mm}$, there is no clear distinction between reference and nanofiber interlayered composites. However, the contribution of adhesive interlayers became apparent in $G_{C}$ value after crack length of $29 \mathrm{~mm}$. The limitations in crack propagation path enabled higher energy dissipation, which was interpreted as $0.7,1$ and 2-fold increase in $G_{C}$ at fracture for $0.5 \mathrm{wt} . \%, 1 \mathrm{wt} . \%$ and $2 \mathrm{wt} . \%$ CNTs nanofiber 
interlayered composites compared to non-interlayered composites, respectively. The increase in $G_{C}$ was in line with the observations of Siddiqui et al where both initiation and propagation $G_{I C}$ increased in nanoclay reinforced carbon fiber composites under Mode I loading [61]. Our results revealed that the highest $G_{C F}$ was calculated in $1 \mathrm{wt} . \%$ CNTs nanofiber interlayered composites, revealing $1.88 \pm 0.2 \mathrm{KJ} / \mathrm{m}^{2}$ at the crack length of $55 \mathrm{~mm}$. On the other hand, increasing CNTs concentration from 1 wt.\% to 2 wt.\% caused a slight decrease in $G_{C F}$, which could be attributed to uneven distribution of higher number of CNTs, as given in Table 2. This phenomenon was also observed by Silva et al. [4] in poorly nanotoughened composites by MWCNTs.

It is noteworthy that a single layer of PVB and PVB/CNTs nanofibrous interlayers prompted gradual crack growth rather than sudden delamination failure in laminated composites. More remarkably, while non-interlayered composites tolerated cracks up to $40 \mathrm{~mm}$, all nanofiber interlayered composite revealed crack length of $55 \mathrm{~mm}$ by restraining the crack propagation at the interface, as displayed in Fig 5. We should also emphasize that $G_{C}$ of nano-interlayered composites increased and then tended to stabilize [4]. On the other hand, non-interlayered composites were not able to sustain this characteristic, thus leading to premature failure. Solely, PVB nanofibers still gave rise to $G_{C F}$ fracture energy and assisted arresting cracks. But it is clear that $G_{C F}$ of PVB nanofibers, $0.8 \pm 0.01 \mathrm{KJ} / \mathrm{m}^{2}$, was much lower than that of $1 \mathrm{wt} . \% \mathrm{CNTs}$ nanofiber interlayered composites, $1.88 \pm 0.2 \mathrm{KJ} / \mathrm{m}^{2}$. The contribution of well distributed CNTs network led such improvement in fracture energy. In our previous studies [15, 24], we noted that CNTs were efficiently placed in the polymeric nanofibers as supplementary pin-like reinforcing elements. Electrospinning process enabled the incorporation of CNTs into PVB nanofibers, which eventually increased further the mechanical performance of interlayers and also behaved as local nano-scaled stiff obstacles. Nevertheless, in PVB/CNTs nanointerlayered composites, retardation in crack propagation was promoted by the synergetic effect of CNTs in 
PVB adhesive layer. Their effectiveness in bridging cracks was strongly dependent on the distribution of CNTs in the polymers, size distribution of CNTs and efficiency of load transfer between CNTs and surrounding matrix, which have been extensively studied by morphological analysis [62-64] and computational studies [65-70]. It was seen that CNTs were acted as obstacles in crack propagation path and required higher energy than soft polymer systems. Thus, cracks preferred to propagate around CNTs, instead of passing through them [71]. This crack bridging mechanism [68] was attributed to pinning effect of CNTs, which was effective both in opening and sliding modes. The increase in $G_{C F}$ and crack delamination length pointed out the superior toughening of interface with single layer of CNTs reinforced nanofiber interlayer, which benefited from the adhesive sub-phase and stiff nanoparticles. 
Table 2 Crack length mean flexural load and $G_{C F}$ at fracture calculated at 40 and $55 \mathrm{~mm}$ crack length of reference and interlayered composites, respectively.

\begin{tabular}{lccc}
\hline \multicolumn{1}{c}{ Specimen } & $\begin{array}{c}\text { Fracture crack } \\
\text { length }(\mathrm{mm})\end{array}$ & $\begin{array}{c}\text { Mean flexural } \\
\text { load }(\mathrm{N})\end{array}$ & $\begin{array}{c}G_{C F} \\
\left(\mathrm{KJ} / \mathrm{m}^{2}\right)\end{array}$ \\
\hline Reference composite & 40 & $68 \pm 0.1$ & $0.6 \pm 0.01$ \\
\hline $\begin{array}{l}\text { Neat PVB nanofiber } \\
\text { interlayered composite }\end{array}$ & 55 & $61 \pm 0.4$ & $0.8 \pm 0.01$ \\
\hline $\begin{array}{l}\text { 0.5 wt.\% CNTs nanofiber } \\
\text { interlayered composite }\end{array}$ & 55 & $72 \pm 2.9$ & $1.16 \pm 0.09$ \\
\hline $\begin{array}{l}\text { 1 wt.\% CNTs nanofiber } \\
\text { interlayered composite }\end{array}$ & 55 & $90 \pm 5.6$ & $1.88 \pm 0.2$ \\
\hline $\begin{array}{l}\text { 2 wt.\% CNTs nanofiber } \\
\text { interlayered composite }\end{array}$ & 55 & $71 \pm 3.2$ & $1.15 \pm 0.1$ \\
\hline
\end{tabular}

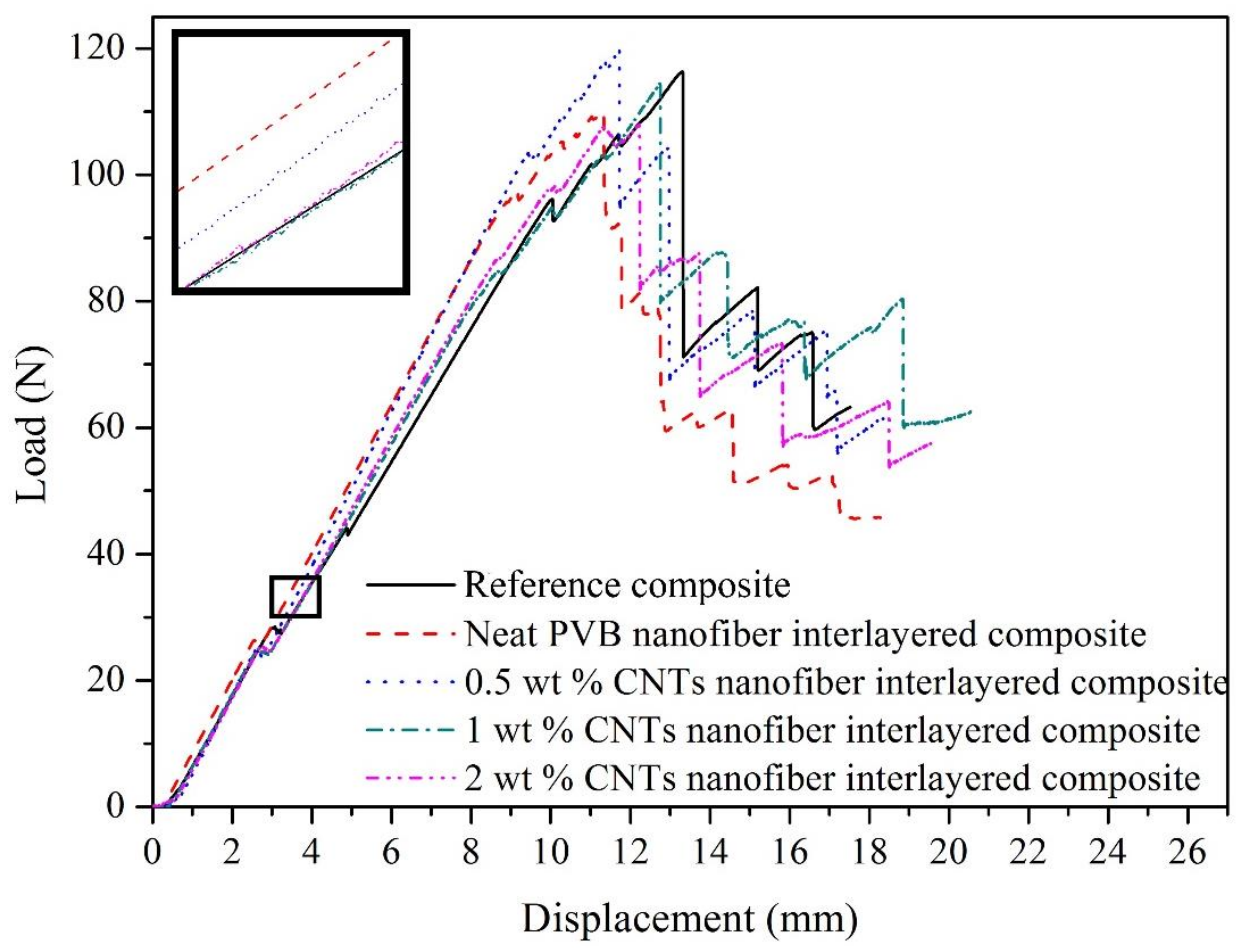

Fig. 4 Representative load vs. load point displacement curves of reference and interlayered composites, framed area points out the zoomed view after $1^{\text {st }}$ crack re-initiation 


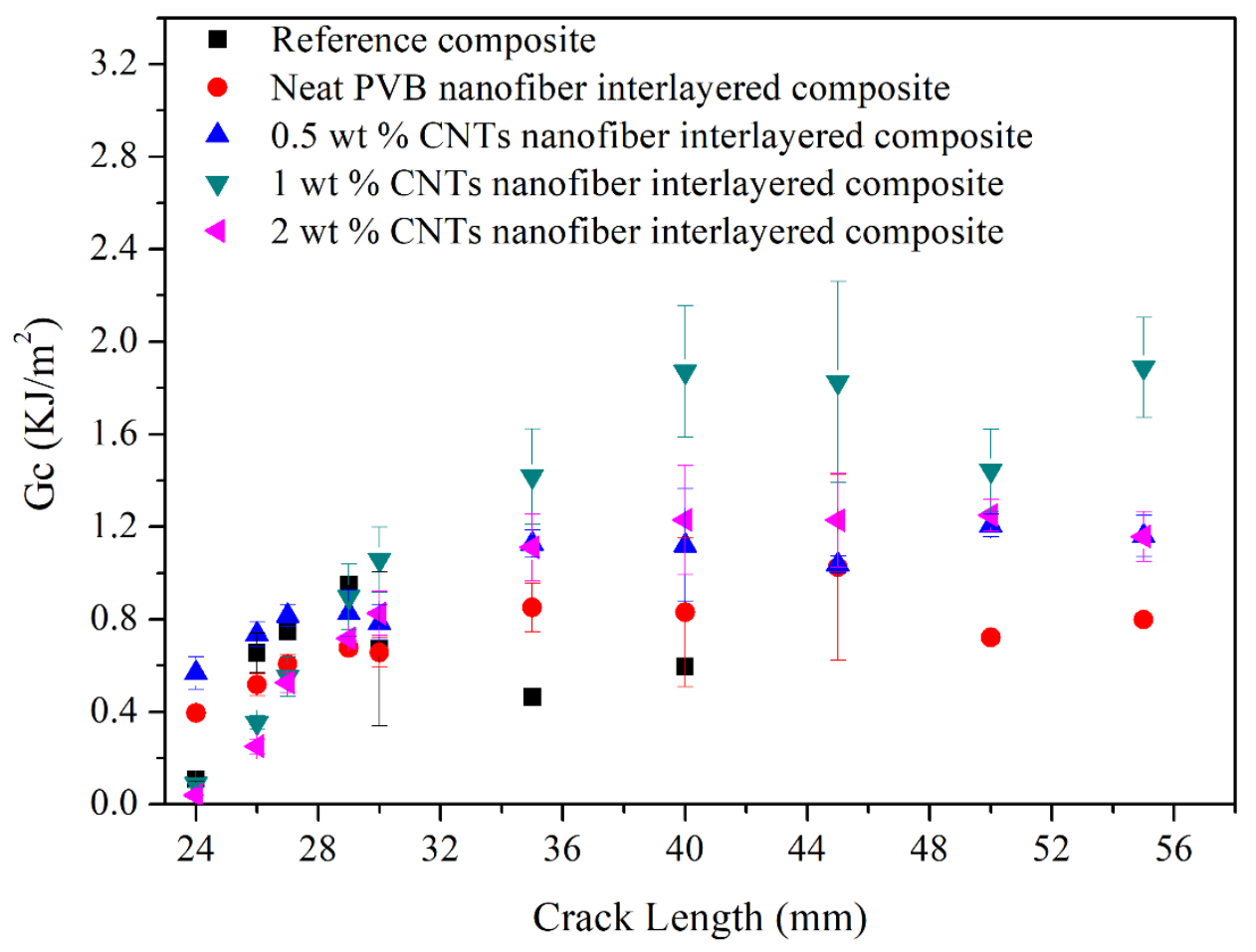

Fig. 5 Mean Mixed-Mode I+II fracture energies, $G_{C}$, with respect to crack length of reference and interlayered composites

The fracture surfaces of MMB specimens were evaluated to trace the microstructural damage marks corresponding to fracture mode. Fig 6 shows fracture surface images of reference noninterleaved laminates after MMB testing. In Fig 6a, initial crack was promoted beyond the boundary smooth surface through the left [72]. Fig 6a also displays the pre-crack area for noninterlayered laminates where crack initiation was started under MMB. As seen in fracture images, failure through warp direction immediately left traces in weft plies. Non-interlayered composites showed smooth fracture surfaces indicating low crack growth resistance of matrix due to the uninterrupted crack propagation in the continuous epoxy matrix.

Complimentary images Fig 6b-f reveal Mode I and Mode II dominated marks as zoomed in Fig 6e and Fig 6f, respectively [73-75]. Zoomed image of Fig 6c exhibits both cusps and fiber breaking belonging to Mode I and Mode II delamination failure [76, 77]. Smooth fracture surfaces observed in fiber bridging area (Fig 6d) implies low resistance to crack propagation 
coherent during MMB tests, which was also observed by Hamer et al. [35]. Fig 6e shows fiber imprint surfaces as secondary deformation occurred due to the extension of crack growth [76]. Furthermore, failure related to fiber breakage was also detected, which was another signature of failure in laminated structures. Owing to the low-resin property of carbon fiber laminates, thin, irregular and shallow cusps were observed [41]. These characteristic features belong to Mode II dominated fractographic marks. Even still, Mode I delamination marks such as fiber bridging was apparent in Fig $\mathbf{6 f}$.

Toughening in the mid-layer in PVB/CNTs interlayered composites left traces in fracture surfaces due to the larger surface area and stronger interaction as seen in Fig 7 [34, 35]. Precrack surface (Fig 7a) of adhesive film interlayered laminates was quite different than resin hackles in non-interlayered composites. For instance, contrary to crack re-initiation region of non-interleaved laminates (Fig 6a), crack propagation path shows rougher and finer patterns indicating effective load transfer [34]. Fig 7b-c reveal Mode I and Mode II dominated surfaces, respectively. These surfaces exhibited distinguishably more rugged faces compared to noninterlayered composites (Fig 6d-f), was thought to be associated with the higher energy absorbance. Fig 7d indicates predominantly adhesive failure of single nanofibrous interlayer composite ply interface, which was clear that polymer adhered to fiber surface. It is noteworthy that PVB bonded both the fiber and epoxy surfaces without creating any voids as displayed in Fig S1. As seen in Fig 7e, crack propagation was deflected by CNTs incorporated nanofibrous layer. Besides, CNTs as crack arresters [24] may create local plastic zones that initiate yielding in the epoxy matrix and/or an increased concentration of crack pinning sites.

Fig 7f shows clearly how adhesive nanofibers changed the surface roughness and prompted pulled-off nanofibers, that also indicated possible nanofiber bridging during loading. The synergetic effect of adhesive PVB nanofiber network and stiff CNTs having pinning effect to deflect crack propagation [25], augmented the reinforcing factor by increasing the plastic zone 
created by the interleaving [78]. Close examination of fracture pattern as seen in Fig $\mathbf{7 f}$ also reveals the presence of micro-scale flakes due to inherent plasticization. Overall, post-SEM analysis on reference and interlayered composites subjected to Mixed-Mode I+II deformation exhibited both the traces of Mode I and Mode II delamination mechanism. We observed that the increase in $G_{C F}$ and crack length was attributed to the combined effect of the two factors: the strength of well dispersed and distributed CNTs in the PVB structure (EDS analysis in Fig S3 was provided to trace well immersed CNTs in PVB structure) and the adhesive PVB electrospun fibers leading to bonding across delamination path. 

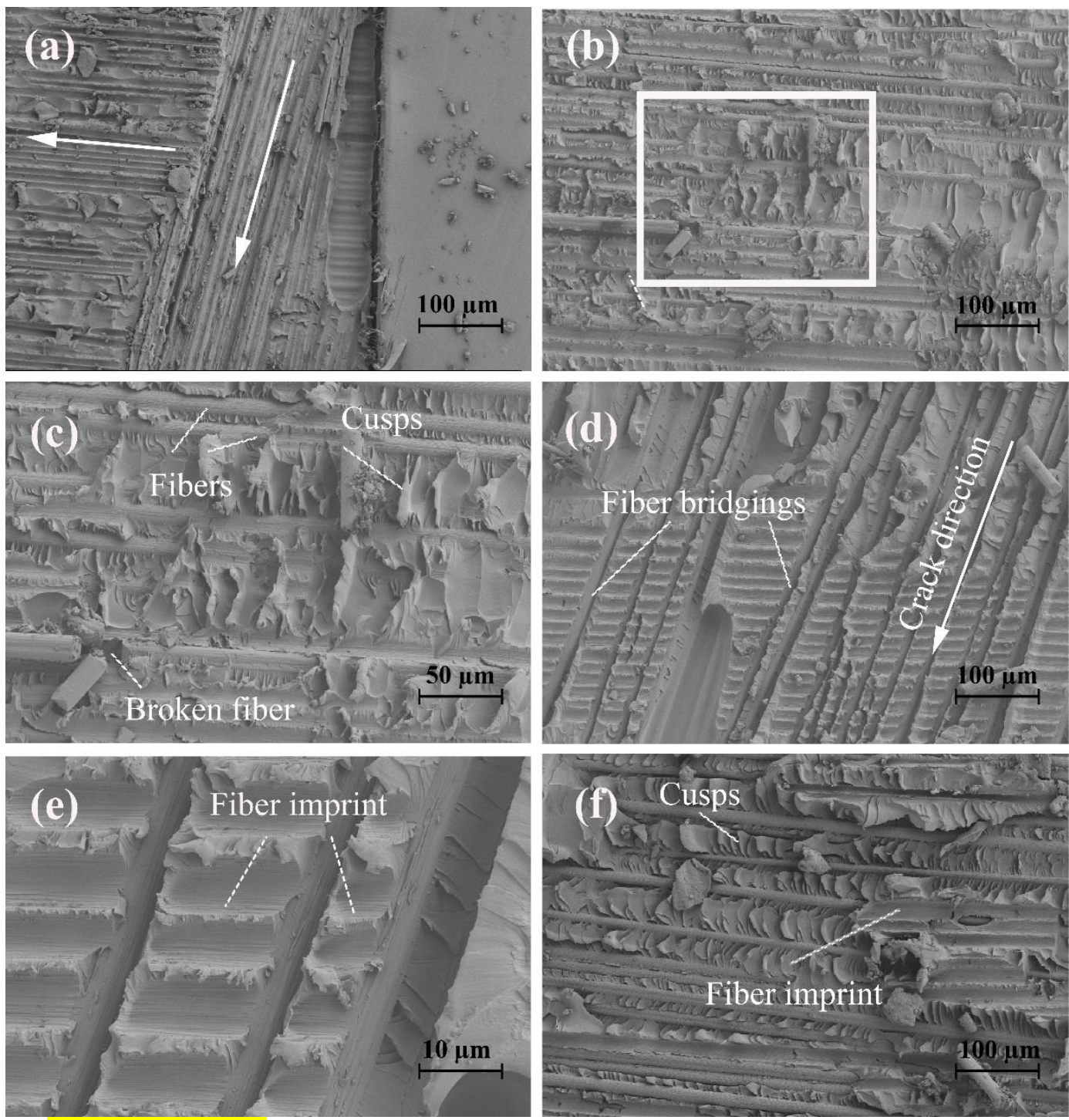

Fig. 6 Non-interlayered laminates fracture surfaces of (a) exhibiting pre-crack area where

white arrows indicate warp and weft directions, (b) Mixed-Mode I+II delamination failure marks, (c) marked area in (b) was zoomed to reveal fracture signs including broken fiber, cusps etc. (d) Mode I dominated surface exhibiting fiber bridgings along crack direction (e), zoomed image of (d) to show fiber imprint (f) Mode II dominated fracture surface 

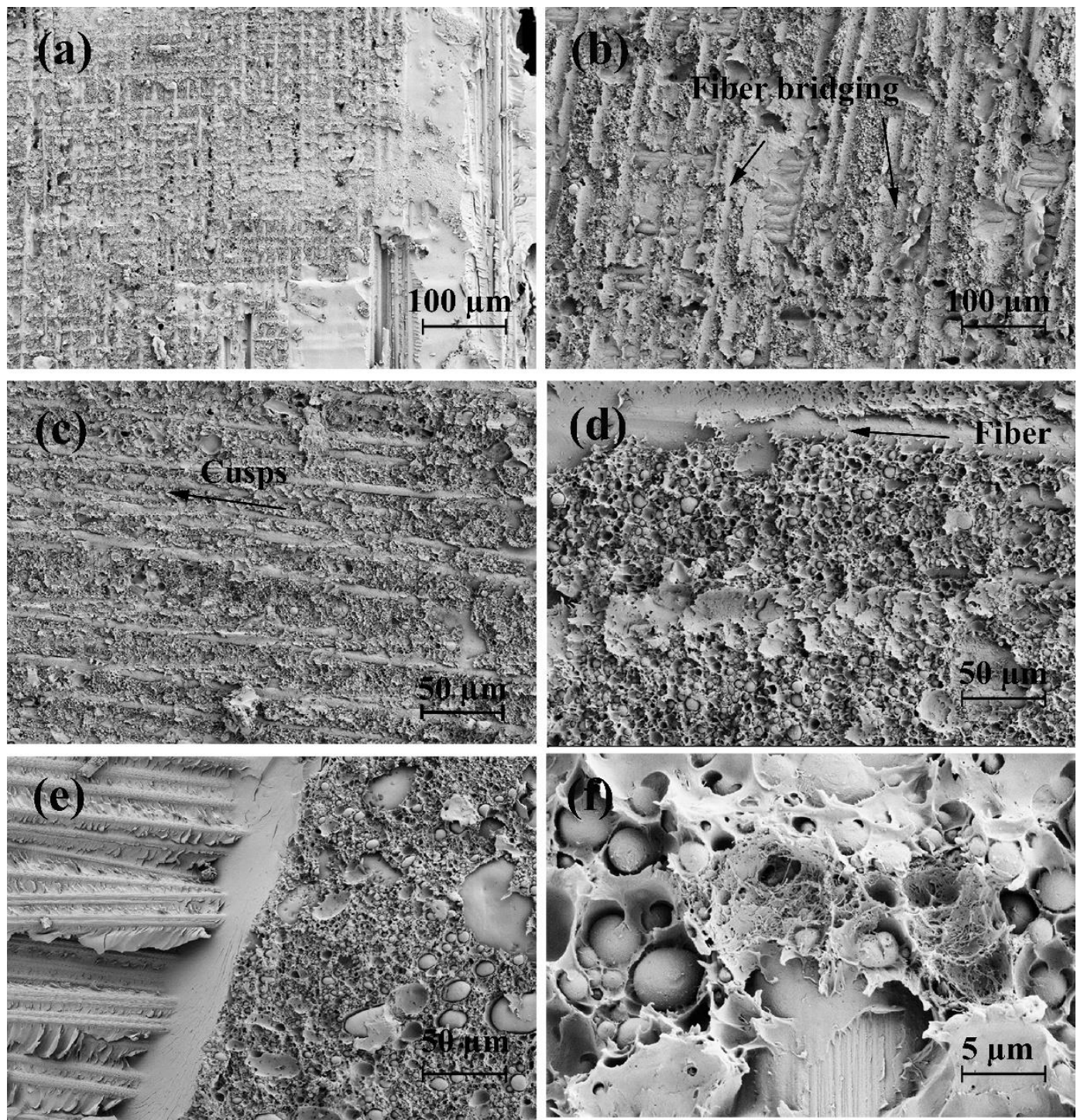

Fig. 7 Fracture surfaces of 1 wt.\% CNT nanofiber interlayered composites revealing (a) pre-

crack area, (b) Mode I dominated fracture surface (c) Mode II dominated fracture surface, (e) cross ply-interlayer interface showing crack deflection, (f) Zoomed in view of (d) exhibiting well interacted adhesive layer across fiber-epoxy surface

\section{Conclusion}

The interlaminar fracture toughness of carbon fiber/epoxy resin laminates have been studied under Mixed-Mode I+II bending loading, where the crack initiated mid-plane has been reinforced with neat PVB and PVB/CNTs adhesive nanofibrous interlayers. To the best of our knowledge, this is the first study which explores the delamination mechanism of CNTs dispersed adhesive nanofibrous networks cured above the $T_{g}$ of nanofibers instead of using them 
as PVB/CNTs nanofibrous webs. MMB tests revealed that the reference non-interlayered composites without any interlayers exhibited essentially linear load increase after crack reinitiation when interlayered composites demonstrated nonlinearity and irregularities in the load increase cycles that was attributable to the adhesive interleaving. Neat PVB and $0.5 \mathrm{wt} . \%$ CNTs interlayered composites were more effective in short delamination length, where adhesiveness of nanofibrous network dominated the crack resistance mechanism. More remarkably, 1 wt.\% and 2 wt.\% CNTs interlayered composites resisted higher deformation and showed significant increase in $G_{C}$, which was thought to be associated with higher weight fractions of CNTs and their ability to behave as local stiff sites to prevent or delay the expansion of microcracking in mid-plane. Besides, 1 wt.\% CNTs nanofiber interlayered composite was also characterized by its load transfer with multiple arrest mechanisms and moderate load drop with $G_{C}$ of $1.88 \pm 0.2$ $\mathrm{KJ} / \mathrm{m}^{2}$ at crack length of $55 \mathrm{~mm}$. Almost 2-fold increase in $G_{C F}$ was reported in PVB/CNTs nano-interlayered composites compared to reference non-interlayered laminates, associated to toughening effect of adhesive PVB/CNTs nanofibrous interlayers. Post-SEM analysis revealed the aid of CNTs incorporated adhesive layers on retarding delamination and afterwards stabilization of crack propagation. It was observed that the fracture mechanism benefited both from the synergetic effect of stiff CNTs and adhesive PVB nanofibers to prompt plasticization and to deflect induced crack propagation by interleaving.

\section{Supporting Information Available.}

\section{Acknowledgment}

The authors thank to TUBITAK 3501 (Project No: 116M427) and TUBITAK 1001 (Project No: 112M807) for the scholarship support of MSc Scholar Ozge Kaynan and MSc Scholar Yagmur Atescan and ITU BAP (Project No: MYL-2017-40710) for material support. The authors also thank Dr. Kaan Bilge for the discussion on fractography and post-SEM analysis, 
Beyza Bozali for help in testing, Sassan Jahangiri for assisting mixed mode specimen preparation, Alptekin Yildiz for his aid in image processing and Ozan Yalcin for video preparation.

\section{References}

1. Kim, J. K., \& Sham, M. L. (2000). Impact and delamination failure of woven-fabric composites. Composites Science and Technology, 60(5), 745-761.

2. Qian, H., Greenhalgh, E. S., Shaffer, M. S., \& Bismarck, A. (2010). Carbon nanotube-based hierarchical composites: a review. Journal of Materials Chemistry, 20(23), 4751-4762.

3. Gong, Y., Zhang, B., \& Hallett, S. R. (2018). Delamination migration in multidirectional composite laminates under mode I quasi-static and fatigue loading. Composite Structures, 189, 160-176.

4. Silva, H., Ferreira, J. A. M., Capela, C., \& Richardson, M. O. W. (2014). Mixed Mode interlayer fracture of glass fiber/nano-enhanced epoxy composites. Composites Part A: Applied Science and Manufacturing, 64, 211-222.

5. Wicks, S. S., Wang, W., Williams, M. R., \& Wardle, B. L. (2014). Multi-scale interlaminar fracture mechanisms in woven composite laminates reinforced with aligned carbon nanotubes. Composites Science and Technology, 100, 128-135.

6. Chen, Q., Zhang, L., Rahman, A., Zhou, Z., Wu, X. F., \& Fong, H. (2011). Hybrid multi-scale epoxy composite made of conventional carbon fiber fabrics with interlaminar regions containing electrospun carbon nanofiber mats. Composites Part A: Applied Science and Manufacturing, 42(12), 2036-2042.

7. Du, X., Zhou, H., Sun, W., Liu, H. Y., Zhou, G., Zhou, H., \& Mai, Y. W. (2017). Graphene/epoxy interleaves for delamination toughening and monitoring of crack damage in carbon fibre/epoxy composite laminates. Composites Science and Technology, 140, 123-133.

8. van der Heijden, S., Daelemans, L., De Bruycker, K., Simal, R., De Baere, I., Van Paepegem, W., ... \& De Clerck, K. (2017). Novel composite materials with tunable delamination resistance using functionalizable electrospun SBS fibers. Composite Structures, 159, 12-20.

9. Blacklock, M., Joosten, M. W., Pingkarawat, K., \& Mouritz, A. P. (2016). Prediction of mode I delamination resistance of z-pinned laminates using the embedded finite element technique. Composites Part A: Applied Science and Manufacturing, 91, 283-291.

10. Ravandi, M., Teo, W. S., Tran, L. Q. N., Yong, M. S., \& Tay, T. E. (2016). The effects of through-thethickness stitching on the Mode I interlaminar fracture toughness of flax/epoxy composite laminates. Materials \& Design, 109, 659-669.

11. Garcia, E. J., Wardle, B. L., Hart, A. J., \& Yamamoto, N. (2008). Fabrication and multifunctional properties of a hybrid laminate with aligned carbon nanotubes grown in situ. Composites Science and Technology, 68(9), 2034-2041.

12. Fan, Z., Santare, M. H., \& Advani, S. G. (2008). Interlaminar shear strength of glass fiber reinforced epoxy composites enhanced with multi-walled carbon nanotubes. Composites Part A: Applied Science and Manufacturing, 39(3), 540-554.

13. Khan, S. U., \& Kim, J. K. (2012). Improved interlaminar shear properties of multiscale carbon fiber composites with bucky paper interleaves made from carbon nanofibers. Carbon, 50(14), 5265-5277.

14. Hossain, M. K., Hossain, M. E., Dewan, M. W., Hosur, M., \& Jeelani, S. (2013). Effects of carbon nanofibers (CNFs) on thermal and interlaminar shear responses of E-glass/polyester composites. Composites Part B: Engineering, 44(1), 313-320.

15. Bilge, K., Ozden-Yenigun, E., Simsek, E., Menceloglu, Y. Z., \& Papila, M. (2012). Structural composites hybridized with epoxy compatible polymer/MWCNT nanofibrous interlayers. Composites Science and Technology, 72(14), 1639-1645.

16. Pham, S., \& Burchill, P. J. (1995). Toughening of vinyl ester resins with modified polybutadienes. Polymer, 36(17), 3279-3285.

17. Ulus, H., Kaybal, H. B., Eskizeybek, V., Sahin, Ö. S., \& Avc1, A. (2017). Static and dynamic mechanical responses of $\mathrm{CaCO} 3$ nanoparticle modified epoxy/carbon fiber nanocomposites. Composites Part B: Engineering, 140, 223-231. 
18. Warrior, N. A., Turner, T. A., Robitaille, F., \& Rudd, C. D. (2004). The effect of interlaminar toughening strategies on the energy absorption of composite tubes. Composites Part A: applied science and manufacturing, 35(4), 431-437.

19. Kobayashi, S., \& Kitagawa, J. (2016). Effect of fine particle incorporation into matrix on mechanical properties of plain woven carbon fiber reinforced plastics fabricated with vacuum assisted resin transfer molding. Composites Part B: Engineering, 85, 31-40.

20. Narducci, F., Lee, K. Y., \& Pinho, S. T. (2018). Interface micro-texturing for interlaminar toughness tailoring: a film-casting technique. Composites Science and Technology, 156, 203-214.

21. Qian, X., Kravchenko, O. G., Pedrazzoli, D., \& Manas-Zloczower, I. (2018). Effect of polycarbonate film surface morphology and oxygen plasma treatment on mode I and II fracture toughness of interleaved composite laminates. Composites Part A: Applied Science and Manufacturing, 105, 138-149.

22. Khan, S. U., \& Kim, J. K. (2012). Improved interlaminar shear properties of multiscale carbon fiber composites with bucky paper interleaves made from carbon nanofibers. Carbon, 50(14), 5265-5277.

23. Ozden, E., Menceloglu, Y. Z., \& Papila, M. (2010). Engineering chemistry of electrospun nanofibers and interfaces in nanocomposites for superior mechanical properties. ACS applied materials \& interfaces, 2(7), 1788-1793.

24. Özden-Yenigün, E., Menceloğlu, Y. Z., \& Papila, M. (2012). MWCNTs/P (St-co-GMA) composite nanofibers of engineered interface chemistry for epoxy matrix nanocomposites. ACS applied materials \& interfaces, 4(2), 777-784.

25. Kim, J. S., \& Reneker, D. H. (1999). Mechanical properties of composites using ultrafine electrospun fibers. Polymer composites, 20(1), 124-131.

26. Dzenis, Y., (2008). Materials science - Structural nanocomposites. Science, 319(5862): p. 419-420.

27. Palmeri, M. J., Putz, K. W., Ramanathan, T., \& Brinson, L. C. (2011). Multi-scale reinforcement of CFRPs using carbon nanofibers. Composites science and technology, 71(2), 79-86.

28. Arai, M., Hirokawa, J. I., Hanamura, Y., Ito, H., Hojo, M., \& Quaresimin, M. (2014). Characteristic of mode I fatigue crack propagation of CFRP laminates toughened with CNF interlayer. Composites Part B: Engineering, 65, 26-33.

29. Bilge, K., Venkataraman, S., Menceloglu, Y. Z., \& Papila, M. (2014). Global and local nanofibrous interlayer toughened composites for higher in-plane strength. Composites Part A: Applied Science and Manufacturing, 58, 73-76.

30. van der Heijden, S., Daelemans, L., De Schoenmaker, B., De Baere, I., Rahier, H., Van Paepegem, W., \& De Clerck, K. (2014). Interlaminar toughening of resin transfer moulded glass fibre epoxy laminates by polycaprolactone electrospun nanofibres. Composites Science and Technology, 104, 66-73.

31. Goodarz, M., Bahrami, S. H., Sadighi, M., \& Saber-Samandari, S. (2017). The influence of graphene reinforced electrospun nano-interlayers on quasi-static indentation behavior of fiber-reinforced epoxy composites. Fibers and Polymers, 18(2), 322-333.

32. Lubineau, G., \& Rahaman, A. (2012). A review of strategies for improving the degradation properties of laminated continuous-fiber/epoxy composites with carbon-based nanoreinforcements. Carbon, 50(7), 2377-2395.

33. Sihn, S., Kim, R. Y., Huh, W., Lee, K. H., \& Roy, A. K. (2008). Improvement of damage resistance in laminated composites with electrospun nano-interlayers. Composites Science and Technology, 68(3-4), 673-683.

34. Arai, M., Noro, Y., Sugimoto, K. I., \& Endo, M. (2008). Mode I and mode II interlaminar fracture toughness of CFRP laminates toughened by carbon nanofiber interlayer. Composites Science and Technology, 68(2), 516-525.

35. Hamer, S., Leibovich, H., Green, A., Avrahami, R., Zussman, E., Siegmann, A., \& Sherman, D. (2014). Mode I and Mode II fracture energy of MWCNT reinforced nanofibrilmats interleaved carbon/epoxy laminates. Composites Science and Technology, 90, 48-56.

36. Palazzetti, R., Zucchelli, A., Gualandi, C., Focarete, M. L., Donati, L., Minak, G., \& Ramakrishna, S. (2012). Influence of electrospun Nylon 6, 6 nanofibrous mats on the interlaminar properties of Gr-epoxy composite laminates. Composite structures, 94(2), 571-579.

37. Beckermann, G. W., \& Pickering, K. L. (2015). Mode I and Mode II interlaminar fracture toughness of composite laminates interleaved with electrospun nanofibre veils. Composites Part A: Applied Science and Manufacturing, 72, 11-21.

38. James, R. (2000). Refinements to the mixed-mode bending test for delamination toughness.

39. ASTM D6671/D 6671M-06. (2006). Standard test method for mixed mode I-mode II interlaminar fracture toughness of unidirectional fiber reinforced polymer matrix composites. 
40. Benzeggagh, M. L., \& Kenane, M. (1996). Measurement of mixed-mode delamination fracture toughness of unidirectional glass/epoxy composites with mixed-mode bending apparatus. Composites science and technology, 56(4), 439-449.

41. Yayla, P. (2016). Fracture Surface morphology of delamination failure of polymer fiber composites under different failure modes. Journal of Failure Analysis and Prevention, 16(2), 264-270.

42. Imaizumi, S., Matsumoto, H., Konosu, Y., Tsuboi, K., Minagawa, M., Tanioka, A., ... \& Windle, A. (2011). Top-down process based on electrospinning, twisting, and heating for producing one-dimensional carbon nanotube assembly. ACS applied materials \& interfaces, 3(2), 469-475.

43. Weng, B., Xu, F., Garza, G., Alcoutlabi, M., Salinas, A., \& Lozano, K. (2015). The production of carbon nanotube reinforced poly (vinyl) butyral nanofibers by the Forcespinning ${ }^{\circledR}$ method. Polymer Engineering \& Science, 55(1), 81-87.

44. Alhazov, D., \& Zussman, E. (2012). Study of the energy absorption capabilities of laminated glass using carbon nanotubes. Composites Science and Technology, 72(6), 681-687.

45. Charitidis, C. A., Koumoulos, E. P., Giorcelli, M., Musso, S., Jagadale, P., \& Tagliaferro, A. (2013). Nanomechanical and tribological properties of carbon nanotube/polyvinyl butyral composites. Polymer Composites, 34(11), 1950-1960.

46. Jahangiri, S., \& Ozden-Yenigun, E. (2018). The stability and dispersion of carbon nanotube-polymer solutions: a molecular dynamics study. Journal of Industrial Textiles, 47(7), 1568-1583.

47. Castori, G., \& Speranzini, E. (2017). Structural analysis of failure behavior of laminated glass. Composites Part B: Engineering, 125, 89-99.

48. Cytec Industrial Materials MTM 49-3. (2012). Retrieved from https://cytec.com/sites/default/files/datasheets/MTM49.pdf

49. Shimizu, A., Kato, H., Sato, T., \& Kushida, M. (2017). Preparation and characterization of oriented poly (vinyl alcohol)/carbon nanotube composite nanofibers. Japanese Journal of Applied Physics, 56(7S2), $07 \mathrm{KD} 02$.

50. Song, Z., Hou, X., Zhang, L., \& Wu, S. (2011). Enhancing crystallinity and orientation by hot-stretching to improve the mechanical properties of electrospun partially aligned polyacrylonitrile (PAN) nanocomposites. Materials, 4(4), 621-632.

51. Datsyuk, V., Trotsenko, S., \& Reich, S. (2013). Carbon-nanotube-polymer nanofibers with high thermal conductivity. Carbon, 52, 605-608.

52. Hadjiev, V. G., Iliev, M. N., Arepalli, S., Nikolaev, P., \& Files, B. S. (2001). Raman scattering test of single-wall carbon nanotube composites. Applied Physics Letters, 78(21), 3193-3195.

53. Scaffaro, R., Maio, A., \& Tito, A. C. (2012). High performance PA6/CNTs nanohybrid fibers prepared in the melt. Composites Science and Technology, 72(15), 1918-1923.

54. Bilge, K., Ozden-Yenigun, E., Simsek, E., Menceloglu, Y. Z., \& Papila, M. (2012). Structural composites hybridized with epoxy compatible polymer/MWCNT nanofibrous interlayers. Composites Science and Technology, 72(14), 1639-1645.

55. Daelemans, L., van der Heijden, S., De Baere, I., Rahier, H., Van Paepegem, W., \& De Clerck, K. (2016). Damage-resistant composites using electrospun nanofibers: a multiscale analysis of the toughening mechanisms. ACS applied materials \& interfaces, 8(18), 11806-11818.

56. Magniez, K., Chaffraix, T., \& Fox, B. (2011). Toughening of a carbon-fibre composite using electrospun poly (hydroxyether of bisphenol a) nanofibrous membranes through inverse phase separation and interdomain etherification. Materials, 4(11), 1967-1984.

57. Zucchelli, A., Focarete, M. L., Gualandi, C., \& Ramakrishna, S. (2011). Electrospun nanofibers for enhancing structural performance of composite materials. Polymers for Advanced Technologies, 22(3), 339-349.

58. Ö̈zden-Yenigün, E., Bilge, K., Sünbüloğlu, E., Bozdağ, E., \& Papila, M. (2017). High strain rate response of nanofiber interlayered structural composites. Composite Structures, 168, 47-55.

59. Dharmawan, F., Simpson, G., Herszberg, I., \& John, S. (2006). Mixed mode fracture toughness of GFRP composites. Composite Structures, 75(1-4), 328-338.

60. Bilge, K., Yilmaz, B., \& Papila, M. (2016). Sound-tracking of failure events in cross-ply composite laminates under tension. Composite Structures, 153, 421-427.

61. Siddiqui, N. A., Woo, R. S., Kim, J. K., Leung, C. C., \& Munir, A. (2007). Mode I interlaminar fracture behavior and mechanical properties of CFRPs with nanoclay-filled epoxy matrix. Composites Part A: Applied science and manufacturing, 38(2), 449-460. 
62. Tang, L. C., Zhang, H., Wu, X. P., \& Zhang, Z. (2011). A novel failure analysis of multi-walled carbon nanotubes in epoxy matrix. Polymer, 52(9), 2070-2074.

63. Fiedler, B., Gojny, F. H., Wichmann, M. H., Nolte, M. C., \& Schulte, K. (2006). Fundamental aspects of nano-reinforced composites. Composites science and technology, 66(16), 3115-3125.

64. Shtein, M., Nadiv, R., Lachman, N., Wagner, H. D., \& Regev, O. (2013). Fracture behavior of nanotube-polymer composites: Insights on surface roughness and failure mechanism. Composites Science and Technology, 87, 157-163.

65. Romano, G., \& Barretta, R. (2017). Stress-driven versus strain-driven nonlocal integral model for elastic nano-beams. Composites Part B: Engineering, 114, 184-188.

66. Barretta, R., Čanadija, M., Feo, L., Luciano, R., de Sciarra, F. M., \& Penna, R. (2017). Exact solutions of inflected functionally graded nano-beams in integral elasticity. Composites Part B: Engineering, 142, 273-286.

67. Romano, G., Barretta, R., \& Diaco, M. (2017). On nonlocal integral models for elastic nanobeams. International Journal of Mechanical Sciences, 131, 490-499.

68. Cha, J., Jun, G. H., Park, J. K., Kim, J. C., Ryu, H. J., \& Hong, S. H. (2017). Improvement of modulus, strength and fracture toughness of CNT/Epoxy nanocomposites through the functionalization of carbon nanotubes. Composites Part B: Engineering, 129, 169-179.

69. Barretta, R., Faghidian, S. A., \& Luciano, R. (2018). Longitudinal vibrations of nano-rods by stress-driven integral elasticity. Mechanics of Advanced Materials and Structures, 1-9.

70. Barretta, R., Faghidian, S. A., Luciano, R., Medaglia, C. M., \& Penna, R. (2018). Stress-driven two-phase integral elasticity for torsion of nano-beams. Composites Part B: Engineering, 145, 62-69.

71. Opelt, C. V., Becker, D., Lepienski, C. M., \& Coelho, L. A. (2015). Reinforcement and toughening mechanisms in polymer nanocomposites-carbon nanotubes and aluminum oxide. Composites Part B: Engineering, 75, 119-126.

72. Stevanovic, D., Jar, P. Y., Kalyanasundaram, S., \& Lowe, A. (2000). On crack-initiation conditions for mode I and mode II delamination testing of composite materials. Composites Science and Technology, 60(9), 1879-1887.

73. Nikbakht, M., \& Choupani, N. (2009). Experimental investigation of mixed-mode fracture behaviour of woven laminated composite. Journal of materials science, 44(13), 3428-3437.

74. Asp, L. E., Sjögren, A., \& Greenhalgh, E. S. (2001). Delamination growth and thresholds in a carbon/epoxy composite under fatigue loading. Journal of Composites, Technology and Research, 23(2), 55-68.

75. Greenhalgh, E. S., \& Singh, S. (2002). The effect of moisture, matrix and ply orientation on delamination resistance, failure criteria and fracture morphology in CFRP. In Composite Materials: Testing, Design, and Acceptance Criteria. ASTM International.

76. Grauers, L., Olsson, R., \& Gutkin, R. (2014). Energy absorption and damage mechanisms in progressive crushing of corrugated NCF laminates: Fractographic analysis. Composite Structures, 110, 110-117.

77. Greenhalgh, E. (2009). Failure analysis and fractography of polymer composites. Elsevier.

78. Yasaee, M., Bond, I. P., Trask, R. S., \& Greenhalgh, E. S. (2012). Mode II interfacial toughening through discontinuous interleaves for damage suppression and control. Composites Part A: Applied Science and Manufacturing, 43(1), 121-128. 